\title{
Dalí and the double helix
}

\section{Science fascinated the great surrealist, who combined it with angels and allegories.}

Sir-Some of the recent articles on the influence of DNA molecule structure and genetics on contemporary art (see, for example, www.nature.com/nature/ DNA50) refer to Salvador Dalí, the renowned Catalonian surrealist artist, and to one of his paintings in particular: Butterfly Landscape, the Great Masturbator in Surrealist Landscape with DNA.

Dalí (1904-1989) was highly interested in science. In the 1930s, his interest focused on dual images and illusions; in 1940 he turned to Planck's quantum theory; and in 1945 the nuclear, or atomic, period of his work began. In the 1950s, 'corpuscular' painting led Dalí to nuclear mysticism. Between 1955 and 1978, his work was deeply influenced by genetics in particular, and especially by DNA and its structure.

When Dalí read Watson and Crick's 1953 Nature article, he said: "It is the real proof of the existence of God." After that, DNA influenced his paintings and many other activities. DNA was present in at least nine paintings from 1956 to 1976: Still Life, Fast Moving (1956), "the decomposition of a fruit dish", metaphorically summarized man's post-atomic understanding of nature. Dalí suggested that there is still a cosmic order in the Universe by incorporating spirals into the composition; he felt that the spiral was the basic form of life, an idea that was confirmed by Crick and Watson in 1953.

Butterfly Landscape, the Great Masturbator in Surrealist Landscape with DNA (1957-1958) locates a prettified evocation of a space-filling model in one of Dalí's typically barren landscapes inhabited by sub-Freudian enigmas. The title of the painting Galacidalacidesoxyribonucleicacid (1963) combines DNA with Dalí's own name and that of his wife, Gala. It represents the three parts of existence: life (DNA structure), death (represented by men with rifles) and life after death (represented by God).

Dalî's fascination with the subject influenced a series of other paintings, some of them reworking similar themes and using similar titles. Desoxyribonucleic Acid Arabs was painted around 1963. Hommage à Crick et Watson (1963) - a name that was also given as a sub-title for the tonguetwisting Galacidalacidesoxyribonucleicacid — includes a picture of the scientists and the legends "Watson: a model builder" and "Crick: Life is a three-letter word". DNA Representation (Jacob's Ladder) (1971) was

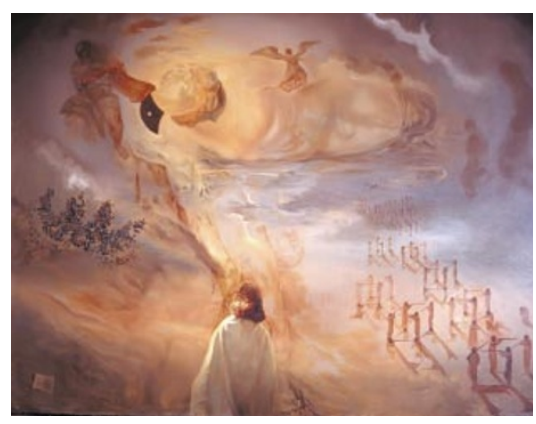

A surrealist view of the meaning of life:

Galacidalacidesoxyribonucleicacid, 1963.

part of the tribute to F. Duran Reynals held at the 1971 National Conference of the Spanish Society of Biochemistry. The structure of DNA is mixed together with angels in Jacob's ladder. Deoxyribonucleic Acid and Jacob's Ladder (1975) is a

\section{Crystal: ever-evolving and expanding in scope}

Sir - In his Concepts essay "Crystal: In search of clarity” (Nature 423, 485; 2003)

Gautam R. Desiraju asserts that "to a scientist, 'crystal' denotes solid matter in a more or less ordered form ... According to the International Union of Crystallography, a crystal is any solid that gives a discrete X-ray diffraction diagram."

Yet there is more to crystals than solidity, for condensation into symmetrical arrays can be governed by repulsive as well as attractive forces. Some ordered arrays that fulfil the criterion of symmetrical diffraction consist not of atoms or molecules, but of discrete objects, or even organisms, such as the Iridoviridae. The rainbow diffraction of visible light by ordered arrays of hydrous silica microspheres is familiar as the play of colour in precious opal, but few realize that an equally arresting display can be seen when such microspheres are widely separated in aqueous suspension by electrostatic forces and Debye screening. The colourful diffraction testifies to long-range order, yet fish can swim through this crystalline glory and it reassembles in their wake.

There are also crystals of crystals, as monocrystalline nanoparticles are equally susceptible to falling into line in repulsive lattices, macrocrystallites of metals in planetary cores, and vast domains of crystalline order created within neutron stars by the strong nuclear force. Good luck in trying to detect their diffraction pattern. surrealistic representation of the DNA structure, with angels ascending and descending the ladder. Two paintings called The Structure of DNA (1975-1976), represent DNA structures with different coloured backgrounds.

Dalí was fascinated by DNA: "Every half of a shoot is exactly linked to its matching half, just as Gala was linked to me ... It all opens and closes and interlinks with amazing precision. Heredity depends on a sovereign mechanism, and life is the product of absolute rule of deoxyribonucleic acid".

Elena Guardiola ${ }^{\star} \uparrow$, Josep-E. Baños $\dagger$

*Unit of Medical Information and Documentation, ReD Department, Q F Bayer, Calabria 268, 08029 Barcelona, Spain

$\dagger$ Department of Experimental and Health Sciences. Universitat Pompeu Fabra, Dr Aiguader 80, 08003 Barcelona, Spain
At the limit of artifice are ordered arrays of atoms assembled by manipulation, which can defy the criterion of least energy that Desiraju's fascinating piece invokes. The many ramifications of this include the possibility of creating deliberate arrays of stable isotope atoms. This has important technical ramifications, for while the ballistic phonon free path, and the thermal conductivity of diamond (illustrated in the Concepts essay) can be enhanced by reducing the carbon 13 level in synthetic diamond feed stocks, that improvement can be transcended only when entropy as well as free energy is defied by ordering isotope defects instead of letting a random cloud of anharmonic oscillators destroy the thermal transport capacity of an otherwise perfect lattice (see R. Seitz, Science 250, 1194-1195; 1990).

Desiraju is certainly right in observing that "the meaning and scope of the term 'crystal' can only evolve and expand". Russell Seitz

13 Cliff Road, Nantucket,

Massachusetts 02554, USA

\section{Crystal: clear difference from glass}

Sir - In his otherwise excellent Concepts essay (Nature 423, 485; 2003) Gautam R. Desiraju proposes that a scientist and a layperson may have different ideas about how to define a crystal. He even mentions that Spanish speakers "have only one word (cristal) for both 'glass' and 'crystal." 
This comment is not totally rigorous. The Spanish Real Academia dictionary (www.rae.es) shows two clearly distinct definitions that I have translated: "(1) glass (vidrio), (from Latin vitrum): solid, fragile material, transparent, without crystalline structure [...]; (2) crystal (cristal), (from Latin crystallus): solid material whose atoms and molecules are regularly and repeatedly distributed in space."

However, it is true that in Spain we use the word cristal for both concepts in colloquial terms.

Bruno Contreras Moreira

Biomolecular Modelling Laboratory,

Cancer Research UK, 44 Lincoln's Inn Fields,

London WC2A 3PX, UK

Gautam R. Desiraju replies - The word cristal is most commonly used in Spanish to describe crystal and glass, unlike the English language, where 'crystal' refers only to high-quality glass, cut glass and so on. The word vidrio is not used so frequently.

\section{Online comment could promote unfair criticism}

Sir_-David M. Eagleman and Alex O. Holcombe in their Correspondence "Improving science through online commentary" (Nature 423, 15; 2003) have proposed a web-based public arena for post-publication comment on scientific papers. Although we share these authors' concern that the slowness of peerreviewed publication holds up comment and rapid (or even any) transmission of corrections, thereby impeding scientific progress, we believe that their proposed solution, a direct link between a website and PubMed entries, itself suffers from difficulties.

Perhaps the most worrisome issue is the likely prevalence of axe-grinding and hidden vested interests on a notice board that is meant for posting logical flaws, experimental weaknesses, questionable assumptions, alternative explanations and even non-replications. Although the proposed moderator could perhaps filter out overtly hostile or libellous notes, it is hard to imagine that he or she would be able to evaluate data adduced as evidence of non-replication.

The idea of post-hoc review is a good one, but Eagleman and Holcome's proposed model amounts to a free-for-all, which might encourage ill-considered comment with the potential for damaging worthy science and scientists. One alternative is to provide independent scientific assessment of published papers directly linked to PubMed, as in a subscription service in which we participate (see www.facultyof1000.com). Andrew Lumsden*, Martin Raff $\dagger$, Joshua R. Sanes

${ }^{*} M R C$ Centre for Developmental Neurobiology, King's College London, Guy's Hospital,

London SE1 1UL, UK

$\dagger M R C$ Laboratory for Molecular Cell Biology and Cell Biology Unit, University College London,

London WC1E 6BT, UK

$\ddagger$ Department of Anatomy and Neurobiology, Washington University Medical Center,

St Louis, Missouri 63110, USA

\section{MRC planning outweighs excellence in science}

Sir - The comprehensive and harsh criticism of the UK Medical Research Council (MRC) by the House of Commons Select Committee for Science and Technology (see Nature 422, 461 and 422, $545 ; 2003$ ) has been considered excessive by some but in my opinion is welcome: British science has found a friend. However, in view of the fact that the MRC supports about half the biomedical research in the United Kingdom, I am surprised that there has been no subsequent debate in Nature or the UK national press.

The select committee criticizes the MRC's practice of funding super-large research centres, long-running cooperative grants and interdisciplinary research groups, which leaves almost no funds for independent and young scientists. Closing or downsizing already existing centres with a reputation (such as the MRC's National Institute for Medical Research: see Nature $422,545$ and 423,$573 ; 2003)$ to free funds for a new one is even more puzzling.

I would like to give my own view on some of the MRC's problems. First, timing is crucial: creating a huge centre before the people who will run it are identified has risks. If the centre does not work, it is likely that its leader will retire before this becomes evident, and others will be blamed for the failure. In the meantime, other scientists will be deprived of funding.

George Radda, the MRC's current chief executive, says that if there had been no far-reaching goals 50 years ago, the double-helix structure of DNA would not have been solved. But this advance, as well as the solution of the first protein structures and protein sequencing, were made possible by three visionaries: John Bernal, Lawrence Bragg and John Randall. They had gathered the right people for the tasks and were powerful enough to obtain money from anywhere. The MRC deserves credit for funding these projects, but it did not hurry to create a new huge and expensive research centre in order to do so.
The MRC Laboratory of Molecular Biology (LMB) in Cambridge was created more than ten years later, after six Nobel prizes were awarded and the seventh was in the pipeline. At that time, the MRC recognized that there was already a critical mass of scientists with proven abilities and that funding such a large institution would repay the investment. They were right: the LMB kept attracting more able scientists and several more Nobel prizes were won subsequently.

My second concern is how and why the system of awarding the remaining scarce money for grants was changed. Peerreview assessment is fundamental to the funding of science. In the past, project proposals were assessed by three to four referees, chosen by the relevant MRC committee. Now, proposals are sent to 24 referees and judged when about eight have replied. It is hard to imagine that they would all be well-informed (in my field, there are not 24 centres anywhere that are actively involved in research). Thus, referees are chosen by administrators, who do not have a broad view on who is competent to judge a project, instead of being chosen by practising scientists. The power has shifted from scientists to administrators.

My third concern is the system of marking of the projects: alpha (recommended for funding), beta (with reservations) and gamma (failed). The alpha projects are additionally subdivided, the highest being alpha-A. Many projects are marked alpha-A, several times more than there is money to fund. They cannot all be equally good, but because they all have the same mark, the committee is given the power to choose which grants to support on political or 'strategic' grounds, independent of merit. Moreover, 'strategic' funding can prejudice the chances of other, perhaps better, projects, as the MRC will consider that it already supports work in that field and that it prefers to shift funds to another field in the strategic plan.

\section{Dontcho Staynov}

Department of Asthma, Allergy and Respiratory Science, 5th Floor, Thomas Guy House, Guy's Hospital, London SE1 9RT, UK

\section{Fiendishly clever?}

Sir - Given the low regard in which lawyers are commonly held, was it just coincidence that led to your Special Report on scientists retraining for the legal profession appearing on page 666 (Nature 423, 666-667; 2003)?

Rupert C. Marshall

School of Biological Sciences, Royal Holloway,

University of London, Egham,

Surrey TW20 OEX, UK 